\title{
The Effect of Incisional and/or Intraperitoneal Local Anesthetic Application on Postoperative Pain during Laparoscopic Cholecystectomy
}

\author{
Oguz Ugur Aydin ${ }^{* 1}$, MD., Eda Uysal Aydin², MD., Ozgur Dandin ${ }^{3}$, MD.,Diğdem Ozer Etik ${ }^{4}$, MD, \\ Nedım Cekmen ${ }^{5}$, Ass. Prof. Nermin Gogus ${ }^{6}$, Prof. \\ ${ }^{1}$ Guven Hospital, Department of Surgery, Ankara, TURKEY \\ ${ }^{2}$ Numune Training and Research Hospital Department of Anethesiology, Ankara,TURKEY \\ ${ }^{3}$ Bursa Military Hospital Department of Surgery, Bursa, TURKEY \\ ${ }^{4}$ Bursa Acibadem Hospital Department of Gastroenterology, TURKEY \\ ${ }^{5}$ Guven Hospital, Department of Anesthesiology, Ankara, TURKEY \\ ${ }^{6}$ Numune Training and Research Hospital Department of Anethesiology, Ankara, TURKEY
}

\begin{abstract}
:
Objective - In this study, we aimed to determine the effect of levobupivacaine (LB) application by intraperitoneal, incisional, and both together on postoperative pain after laparoscopic cholecystectomy.
\end{abstract}

\section{Materials and Methods}

One hundred ASA (American Society of Anesthesiologists) I-II patients undergoing laparoscopic cholecystectomy were recruited in the study. The patients were randomized into four groups: placebo group $(P)$, incisional group (I), intraperitoneal group (IP), and the combined (incisional+intraperitoneal) group (C). In the postoperative period, pain in the patients during resting and coughing was evaluated after 30 min, 2, 4, 8, 12, and 24 hours by employing visual analogue scale (VAS) for pain. Applied analgesic quantity, shoulder pain, and the existence of nausea-vomiting were also recorded.

\section{Results}

Pain scores during resting and coughing were significantly lower in the combined group compared with others. Pain scores were similar in the incision and intraperitoneal groups, whereas in the placebo group were significantly lower. The analgesic need was lowest in the combined group and highest in the placebo group. There was no shoulder pain either in the combined or intraperitoneal groups. Nausea-vomiting rates were similar in all groups.

\section{Conclusions}

We conclude that combined application of $0.25 \%$ levobupivacaine can be used as an effective and safe method for postoperative pain control after laparoscopic cholecystectomy.

\section{Introduction}

Laparoscopic cholecystectomy is the gold standard treatment for symptomatic gallbladder stones and gallbladder polyps, and currently it has become the most used laparoscopic surgical procedure. [1] Compared with open cholecystectomy, it provides faster recovery and causes less surgical trauma.[2,3] Although traditional laparoscopic cholecystectomy method is performed by four ports, recently three, two or even one port is also being used for less postoperative pain and better cosmetic results. However, in the early postoperative period of 


\section{International Journal of Innovative Research in Medical Sciences (IJIRMS) \\ ISSN (Online): 2455-8737, page No. 207 to214 \\ Volume 01, Issue 05, July 2016}

laparoscopic surgery, most of the patients experience severe stomachache that requires analgesia.[4-7] Postoperative pain usually starts with surgical trauma and ends with tissue healing. Postoperative pain due to laparoscopic surgery originates from the peritoneal irritation caused by the operative stress and presence of $\mathrm{CO}_{2}$ in the abdomen. [8,9] Less frequently, an entrance through abdominal wall by a trocar causes parietal abdominal pain. Peritoneal irritation due to $\mathrm{CO}_{2}$ causes shoulder pain in one-third patients. For pain alleviation several approaches are used, e.g., non-steroidal anti-inflammatory drugs, analgesic applications via catheters, and local anesthesia, as the leading ones.[10,11] Levobupivacaine is an enantiomer of bupivacaine $S(-)$. Compared to bupivacaine, it has milder cardiovascular side effects and central nervous system toxicity. Levobupivacaine offers similar analgesic activity, and being widely used at present.[12]

The objective of this study, determined the effects of applying incisional and/or intraperitoneal local anesthetics and the need of analgesics in the early postoperative period.

\section{Materials and Methods}

After the approval of the institutional ethical committee, one hundred ASA I-II group patients (age 18-65 years) with no mental disorder, planned to undergo laparoscopic cholecystectomy due to chronic signet cholecystitis or gallbladder polypes were recruited. A signed consent form was obtained by all the patients.

All of the patients were examined comprehensively for anamnesis, physical anomaly, general laboratory tests (complete blood count, prothrombin time, activated partial thromboplastin time, electrolytes etc.), and habits (smoking, alcohol use, drug addiction, etc.).

The exclusion criteria were: hypersensitivity to levobupivacaine, psychiatric problems, alcohol or drug addiction, and pregnancy. The study termination criteria included: inefficient patient participation, maladaptations to study criteria, insufficient/wrong data, transition to open cholecystectomy, intraabdominal drain insertion, and insecure applications.

In the preoperational period all patients were introduced to VAS (Visual Analogue Scale) comprehensively and the scoring system was taught to them. Vascular cannulas were inserted to the patients $30 \mathrm{~min}$ before the surgery. The patients were monitored by electrocardiography, heart rate, peripheral oxygen saturation $\left(\mathrm{SpO}_{2}\right)$, end-tidal carbon dioxide pressure $\left(\mathrm{ETCO}_{2}\right)$ and non-invasive blood pressure in the theater. Respiration was mechanically assisted at $7 \mathrm{~mL} \mathrm{~kg}^{-}$ 1 volume (Primus Drager, Lübeck, Germany). $\mathrm{ETCO}_{2}$ was adjusted between 35-40 mmHg. $\mathrm{SpO}_{2}$ was kept above 96\%. Propofol at $2 \mathrm{mg} / \mathrm{kg}$, vecuronium at $0.1 \mathrm{mg} / \mathrm{kg}$, and alfentanil at 10 $\mathrm{mcg} / \mathrm{kg}$ were administered via i.v. route for the anesthesia induction. Anesthesia was maintained with $2 \%$ inspiratory sevoflurane in $50 \% \mathrm{NO}_{2}$ and $50 \% \mathrm{O}_{2}$, and muscle relaxation was maintained with $0.01 \mathrm{mg} / \mathrm{kg}$ vecuronium.

The patients were randomly assigned into four groups: placebo group (P), incisional group (I), intraperitoneal group (IP), and the combined (incisional+intraperitoneal) group (C). To the patients in the $\mathrm{P}$ and IP groups, 5 each cc of $0.9 \%$ $\mathrm{NaCl}$ was injected subcutaneously in trocar insertion sites; to the patients in the I and $\mathrm{C}$ groups, 5 each cc of $0.25 \%$ levobupivacaine was injected subcutaneously in trocar insertion sites. For laparoscopic intervention intraabdominal pressure was adjusted to $12-14 \mathrm{mmHg}$ by making intraperitoneal $\mathrm{CO}_{2}$ insufflation with Veress needle placed at the hypogastrium. Following the completion of laparoscopic surgery and termination of pneumoperitoneum, $20 \mathrm{cc}$ of $0.9 \%$ $\mathrm{NaCl}$ was given to the bed of gallbladder of the patients in the $\mathrm{P}$ and I groups, and $20 \mathrm{cc}$ of $0.25 \%$ levobupivacaine was given to the bed of gallbladder of the patients in the IP and C groups via a catheter. 


\section{International Journal of Innovative Research in Medical Sciences (IJIRMS) \\ ISSN (Online): 2455-8737, page No. 207 to214 \\ Volume 01, Issue 05, July 2016}

All the patients were given $4 \mathrm{mg}$ ondansetron i.v., $75 \mathrm{mg}$ diclofenac i.m., $0.02 \mathrm{mg} / \mathrm{kg}$ neostigmine, and $0.01 \mathrm{mg} / \mathrm{kg}$ atropine, and the anaesthesia was terminated. At the end of the surgical intervention, the patients were extubated by decurarization. The patients whose spontaneous respiration was efficient were taken to the recovery room, and that time was considered as 0 hour. After one hour of observation, stable patients were transferred to the surgery ward. The interval between $0 \mathrm{~h}$ when the patients reached recovery room and the time when they were given analgesic was taken as "analgesic period". Total analgesic consumption in the first $24 \mathrm{~h}$ and the analgesic period were recorded. Besides, the patients were asked, in the first $24 \mathrm{~h}$, if they had nausea-vomiting, xerostomia, itching, palpitation, and headache. Visual analog scales (VAS) for shoulder pain during resting and coughing were recorded at $30 \mathrm{~min}$ and $2,4,8,12$, and $24 \mathrm{~h}$ postoperatively. Whenever VAS score was $\geq 40,1$ $\mathrm{mg} / \mathrm{kg}$ tramadol i.m. was administered.
The data were analyzed by using SPSS 11.5 version. Age, weight, surgical period, pain scores during resting and coughing, and the first analgesic application time for the patients were evaluated by using analysis of variance (ANOVA). Post hoc Tukey's HSD test was done in order to determine the group that the difference originated. Gender, ASA classifications, analgesic requirements, shoulder pain and nausea-vomiting incidences were evaluated by cross tab, chi-square and Pearson's chi-square tests. All data are presented as average \pm standard errors or as number of patients and percentage of patients. In all tests a value of $\mathrm{p}<0.05$ was accepted as statistically significant.

\section{Results}

The demographic characteristics of patients (gender, age, and weight), ASA class, and operation periods were similar between the groups (Table I).

Table I. The demographic characteristics of patients

\begin{tabular}{lccccc}
\hline & $\begin{array}{c}\text { Group P } \\
(\mathbf{n = 2 5})\end{array}$ & $\begin{array}{c}\text { Group I } \\
(\mathbf{n = 2 5})\end{array}$ & $\begin{array}{c}\text { Group IP } \\
(\mathbf{n = 2 5})\end{array}$ & $\begin{array}{c}\text { Group C } \\
(\mathbf{n = 2 5})\end{array}$ & p \\
\hline Gender (M/F) & $11 / 14$ & $9 / 16$ & $7 / 18$ & $11 / 14$ & 0.600 \\
Age (year) & $50.9 \pm 11.7$ & $52.6 \pm 12.5$ & $50.8 \pm 13.4$ & $51.4 \pm 12.2$ & 0.958 \\
Weight (kg) & $67.9 \pm 8.2$ & $65.5 \pm 9.1$ & $65.9 \pm 9.4$ & $62 \pm 8.3$ & 0.127 \\
ASA (I-II) & $10 / 15$ & $8 / 17$ & $11 / 14$ & $10 / 15$ & 0.850 \\
Operation period (min) & $50.2 \pm 21.3$ & $54.1 \pm 24.3$ & $55.6 \pm 21.6$ & $58.4 \pm 27.4$ & 0.672 \\
\hline
\end{tabular}

(P); placebo group,(I); incisional group,(IP); intraperitoneal group,(C); the combined (incisional+intraperitoneal) group

None of the patients had any kind of complication in both intraoperative and postoperative period. Three patients were changed to open cholecystectomy; and drains were inserted in four patients. These patients were excluded from the study.

At postoperative $30 \mathrm{~min}$, similar results were observed in the incisional, intraperitoneal and combined groups during resting, but different results were obtained in the placebo group. At postoperative 2 and $4 \mathrm{~h}$, similar results were observed in the incisional and intraperitoneal groups during resting, but different results were obtained in the combined and placebo groups. At postoperative $8 \mathrm{~h}$, similar results were observed in the incisional, intraperitoneal and combined groups during resting, but different results were obtained in the placebo group. At postoperative 12 $\mathrm{h}$, similar results were observed in the incisional and intraperitoneal groups during resting, but 


\section{International Journal of Innovative Research in Medical Sciences (IJIRMS) \\ ISSN (Online): 2455-8737, page No. 207 to214 \\ Volume 01, Issue 05, July 2016}

different results were obtained in the placebo and combined groups (Figure I).

Figure I: Pain scores during resting in groups

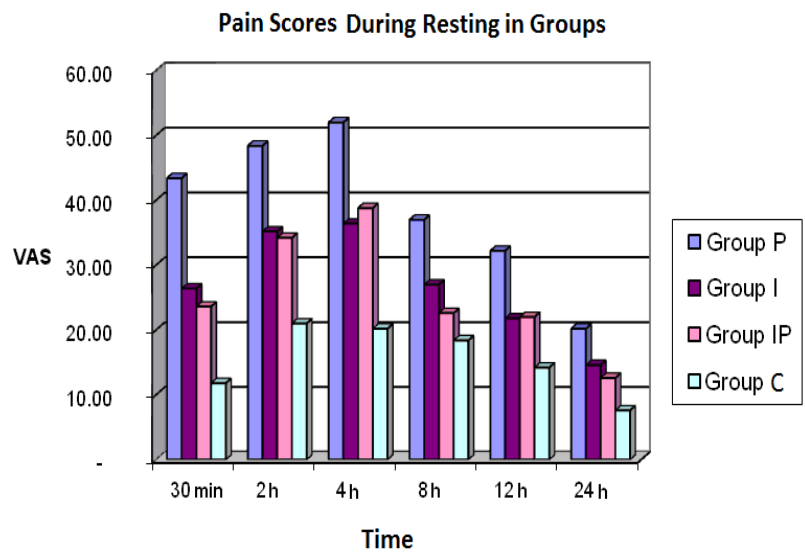

(P); placebo group, (I); incisional group, (IP); intraperitoneal group, $(\mathrm{C})$; combined (incisional+intraperitoneal) group

At postoperative $30 \mathrm{~min}$, similar results were observed in the incisional, intraperitoneal and combined groups during coughing, but different results were obtained in the placebo group. At postoperative $2,4,8,12$, and $24 \mathrm{~h}$, similar results were observed in the incisional and intraperitoneal groups during coughing, but different results were obtained in the placebo and combined groups (Figure II).

Figure II: Pain scores during coughing in groups

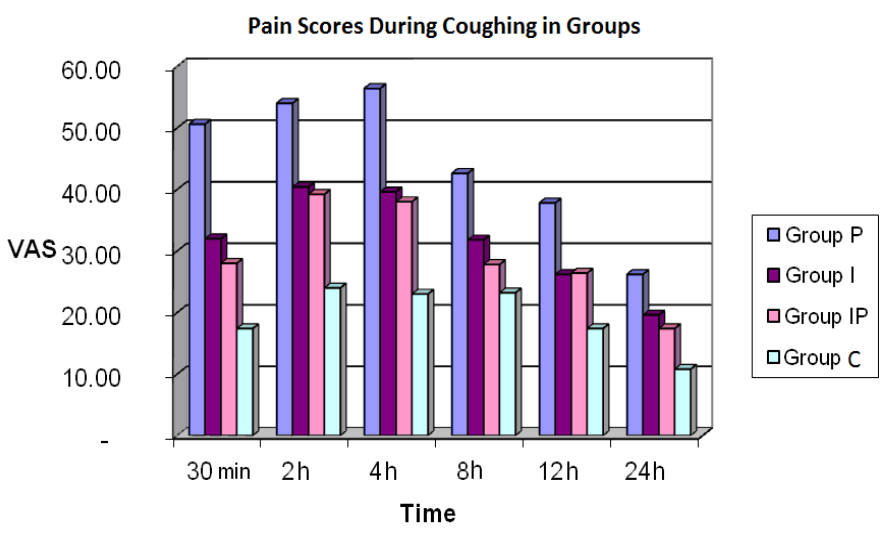

(P); placebo group, (I); incisional group,(IP); intraperitoneal group,(C); combined (incisional+intraperitoneal) group
When analgesic requirements between groups were examined, statistically significant differences were found $(\mathrm{p}<0.05)$. In the placebo group, two patients $(8 \%)$ were not given any analgesic, eight patients (32\%) were given once, 11 patients (44\%) were given twice, and four patients (16\%) were given analgesic thrice. On the other hand, in the incisional group, six patients (24\%) were not given any analgesic, eight patients (32\%) were given once, eight patients (32\%) were given twice, and three patients (12\%) were given analgesic thrice. In contrast to the above two conditions, in the intraperitoneal group six patients $(24 \%)$ were not given any analgesic, 12 patients (48\%) were given once, five patients $(20 \%)$ were given twice, two patients $(8 \%)$ were given the analgesic thrice. In the combined group 14 patients $(56 \%)$ were not given any analgesic, six patients (24\%) were given once, five patients (20\%) were given twice, and no patient had analgesic three times (Table II).

Table II: Analgesic requirements between groups (number of patients \%)

\begin{tabular}{ccccc} 
& Group P & Group I & Group IP & Group C \\
& $(\mathbf{n = 2 5})$ & $(\mathbf{n = 2 5})$ & $(\mathbf{n = 2 5})$ & $(\mathbf{n = 2 5})$ \\
\hline $\mathbf{0}$ & $2(8 \%)$ & $6(24 \%)$ & $6(24 \%)$ & $\mathbf{1 4}(\mathbf{5 6 \%})$ \\
$\mathbf{1}$ & $8(32 \%)$ & $8(32 \%)$ & $12(48 \%)$ & $\mathbf{6}(\mathbf{2 4 \%})$ \\
$\mathbf{2}$ & $11(44 \%)$ & $8(32 \%)$ & $5(20 \%)$ & $\mathbf{5 ( 2 0 \% )}$ \\
$\mathbf{3}$ & $\mathbf{4 ( 1 6 \% )}$ & $\mathbf{3 ( 1 2 \% )}$ & $\mathbf{2 ( 8 \% )}$ & $\mathbf{0}(\mathbf{0 \%})$ \\
\hline
\end{tabular}

(P); placebo group,(I); incisional group,(IP); intraperitoneal group, $(\mathrm{C})$; the combined (incisional+intraperitoneal) group

When first analgesic time between the groups was examined, statistically significant differences were found $(\mathrm{p}<0.05)$. First analgesic requirement time was $34.5 \pm 10.9 \mathrm{~min}$ in the placebo group, $49.4 \pm 8.8$ 


\section{International Journal of Innovative Research in Medical Sciences (IJIRMS) \\ ISSN (Online): 2455-8737, page No. 207 to214 \\ Volume 01, Issue 05, July 2016}

min in the incisional group, $47.3 \pm 10.7 \mathrm{~min}$ in the intraperitoneal group, and $58.5 \pm 13.5 \mathrm{~min}$ in the combine group (Figure III).

Figure III: First analgesic requirement time in groups

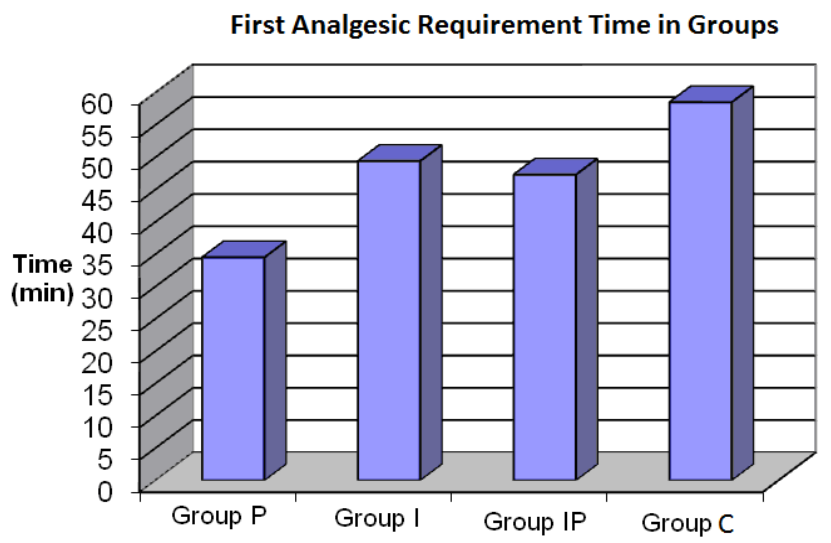

(P); placebo group, (I); incisonal group,(IP); intraperitoneal group,(C); combined (incisional+intraperitoneal) group

In regards to shoulder pain, statistically significant differences were found between the groups $(\mathrm{p}<0.05)$. In the placebo group, five patients $(20 \%)$ had postoperative shoulder pain, while in the incisional group only three patients $(12 \%)$ had. In contrast to this, in the intraperitoneal and combined groups, no patients had shoulder pain.

When postoperative nausea-vomiting was examined, no statistically significant difference was found between the groups $(p>0.05)$. In the placebo group six patients $(24 \%)$, in the incisional group seven patients (28\%), in the intraperitoneal group also seven patients (28\%), and in the combined group only five patients $(20 \%)$ had nausea-vomiting. All incidences, if any, of side and toxic effect, hypotension, arrhythmia, and cyanosis, conceived to be drug-induced, were recorded.

\section{Discussion}

Laparoscopic cholecystectomy is a conventional practice, wherein the minimal invasive technique has recently been added. The pain observed after laparoscopic cholecystectomy is visceral pain originating due to surgical manipulation and diaphragmatic irritation of dissolved $\mathrm{CO}_{2}$ in the abdomen. Some contribution to the pain originates from the incision made in the abdominal wall at the entrance region of trocar. In this study, VAS for pain was used for the evaluation of postoperative pain and scoring system was taught to the patients comprehensively in the postoperative period.

Local anesthetic materials exert antinociceptive effect by affecting nerve membrane. Local anesthetics affect many proteins related to tissue membranes and inhibit oscillation. The movements of agents, such as prostaglandin, sensitize or stimulate nociceptors and contribute to inflammation. The preincisional infiltration of local anesthetics prevents reaching of the nociceptive responses to the central nervous system and represses hyperexcitability responsible for serious postoperative pain.[13-16]

Papagiannopoulou et al [13], in their study, where only incisional levobupivacaine infiltration was done, compared ropivacaine and incisional levobupivacaine infiltration by randomly dividing 57 laparoscopic cholecystectomy patients into three groups $(20 \mathrm{~mL}$ to all groups, before trocar replacement). Since in levobupivacaine group postoperative pain and analgesic requirement were significantly lower compared to the ropivacaine and placebo groups, incisional usage in laparoscopic cholecystectomy was thought to be more effective than ropivacaine. Hasaniye et al [15] divided 100 patients, having laparoscopic cholecystectomy, randomly into two groups before placing trocar, and found that postoperative pain, analgesic usage, and antiemetic usage in the group given incisional bupivacaine was significantly lower compared to the placebo group. We applied $0.25 \%$ levobupivacaine to trocar regions at the end of surgery after taking out the gallbladder intraperitoneally. When levobupivacaine preincisional local infiltration 


\section{International Journal of Innovative Research in Medical Sciences (IJIRMS) \\ ISSN (Online): 2455-8737, page No. 207 to214 \\ Volume 01, Issue 05, July 2016}

and intraperitoneal combination were compared with the placebo group, a decrease in pain during resting and coughing and analgesic requirement for the combined group were observed compared to other groups. Although VAS for pain scores in incisional and intraperitoneal groups were similar to the placebo group; these patients compared to the placebo group needed less analgesic requirement.

İn another study done by Hilvering et al [17] one group was given preincisional $80 \mathrm{~mL}$ of $0.125 \%$ bupivacaine, second group was given preincisional and intraperitoneal same amount of bupivacaine, and a third group was given saline. They found that there was no significant difference between the groups in postoperative pain, and the application of intraperitoneal bupivacaine was thought not to be effective in relieving pain after laparoscopic cholecystectomy. Lee et al [18] the preoperative and postoperative, incisional and intraperitoneal applications of bupivacaine $(0.25 \% 60 \mathrm{~mL})$ were compared. In a group, where preoperative preincisional infiltration was done, the pain was significantly lower than the groups where preoperative or postoperative intraperitoneal local anesthetics were applied. Accordingly, a preoperative preincisional application of a local anesthetic was suggested. We applied $0.25 \%$ levobupivacaine to trocar regions at the end of surgery after taking out the gallbladder intraperitoneally. When levobupivacaine preincisional local infiltration and intraperitoneal combination were compared with the placebo group, a decrease in pain during resting and coughing and analgesic requirement for the combined group were observed compared to other groups.

Gharaibeh et al [19] assigned 75 laparoscopic cholecystectomy patients randomly into two groups. They applied $10 \mathrm{~mL}$ of $0.25 \%$ bupivacaine to gallbladder bed to one group. The other group was not given any local anesthetic. Shoulder pain was found significantly low in group given local anesthetic, and it was concluded that giving local bupivacaine to gallbladder bed is effective in reducing shoulder pain.

In a study done by Louizos et al [20] 104 patients were assigned randomly into four groups. First group was given $20 \mathrm{~mL}$ physiological solution incisional and $20 \mathrm{~mL}$ physiological solution intraperitoneal, second group was given $20 \mathrm{~mL}$ levobupivacaine incisional and $20 \mathrm{~mL}$ physiological solution intraperitoneal, third group was given $20 \mathrm{~mL}$ physiological solution incisional and $20 \mathrm{~mL}$ levobupivacaine intraperitoneal, and fourth group received $20 \mathrm{~mL}$ levobupivacaine incisional and $20 \mathrm{~mL}$ levobupivacaine intraperitoneal. For postoperative pain $1 \mathrm{mg} / \mathrm{kg}$ meperidine i.m. and $8 \mathrm{mg}$ lornoxicam i.v. were applied at the beginning of surgery. When postoperative VAS value was over 40, dextropropoxyphene $75 \mathrm{mg}$ i.m. was given and, at the end, the application of intraperitoneal levobupivacaine was found to be effective on palliation of right shoulder pain. In our study right shoulder pain was thought to be significantly low only in intraperitoneal and combined local anesthetic group. We also obtained similar results in our study; however, our standard analgesic doses (i.m. and i.v.) were low. Despite intraperitoneal and incisional levobupivacaine applications, we thought that preoperative sedation and additional analgesic doses are high for laparoscopic cholecystectomy, which is a noninvasive surgical technique.

Nausea-vomiting are the symptoms that the patients complain frequently after laparoscopic cholecystectomy. In our study, it was observed that local analgesic methods that we used did not have any effect on nausea-vomiting incidence.

Our study, the postoperative additional analgesic requirement was reduced by an intraperitoneal and incisional combined local application of anesthetics; and during postoperative period low pain scores were obtained. However, no 


\section{International Journal of Innovative Research in Medical Sciences (IJIRMS) \\ ISSN (Online): 2455-8737, page No. 207 to214 \\ Volume 01, Issue 05, July 2016}

evaluation was done in terms of time and volume. The ineffectiveness of a local anesthetic can arise from improper application time or insufficient volume. That is why we think that future studies should be done in terms of timing and volume. We suggest that incisional and intraperitoneal local anesthetic application in laparoscopic cholecystectomy is an effective and secure method in treatment of postoperative pain.

\section{Conclusion}

We conclude that preincisional local infiltration of levobupivacaine with its intraperitoneal combination is an effective and safe technique in postoperative pain control. This is also a feasible way for patients who are going through laparoscopic cholecystectomy.

\section{References}

1. Sun S, Yang K, Gao M, He X, Tian J, Ma B. Three-port versus four-port laparoscopic cholecystectomy: metaanalysis of randomized clinical trials. World J Surg. 2009; 33: 1904-1908.

2. Abd Ellatif ME, Askar WA, Abbas AE, Noaman N, Negm A, El-Morsy G, El Nakeeb A, Magdy A, Amin M. Quality-oflife measures after single-access versus conventional laparoscopic cholecystectomy: a prospective randomized study. Surg Endosc. 2013; 27: 1896-1906.

3. Enes H, Semir I, Sefik H, Husnija M, Goran I. Postoperative pain in open vs. laparoscopic cholecystectomy with and without local application of anaesthetic. Med Glas (Zenica). 2011; 8: 243-248.

4. El-Labban GM, Hokkam EN, El-Labban MA, Morsy K, Saadl S, Heissam KS. Intraincisional vs. intraperitoneal infiltration of local anaesthetic for controlling early post-laparoscopic cholecystectomy pain. J Minim Access Surg. 2011; 7: 173-177.
5. Honca M, Kose EA, Bulus H, Horasanli E. The postoperative analgesic efficacy of intraperitoneal bupivacaine compared with levobupivacaine in laparoscopic cholecystectomy. Acta Chir Belg. 2014; 114: 174-178.

6. Gurusamy KS, Nagendran M, Guerrini GP, Toon CD, Zinnuroglu M, Davidson BR. Intraperitoneal local anaesthetic instillation versus no intraperitoneal local anaesthetic instillation for laparoscopic cholecystectomy. Cochrane Database Syst Rev. 2014; 3: CD007337.

7. Papadima A, Lagoudianakis EE, Antonakis P, Filis K, Makri I, Markogiannakis H, Katergiannakis V, Manouras A. Repeated intraperitoneal instillation of levobupivacaine for the management of pain after laparoscopic cholecystectomy. Surgery. 2009; 146: 475482.

8. Castillo-Garza G, Díaz-Elizondo JA, Cuello-García CA, Villegas-Cabello O. Irrigation with bupivacaine at the surgical bed for postoperative pain relief after laparoscopic cholecystectomy. JSLS. 2012; 16: 105-111.

9. LeBlanc Louvry I, Coquerel A, Koning E, Maillot C, Ducrotté P. Operative stress response is reduced after laparoscopic compared to open cholecystectomy. Dig Dis Sci. 2000; 45: 1703-1713.

10. Block BM, Liu SS, Rowlingson AJ, Cowan AR, Cowan JA Jr, Wu CL. Efficacy of postoperative epidural analgesia: a meta-analysis. JAMA. 2003; 290: 2455-2463.

11. Ng A, Swami A, Smith G, Davidson AC, Emembolu J. The analgesic effects of intraperitoneal and incisional bupivacaine with epinephrine after total abdominal hysterectomy. Anesth Analg. 2002; 95: 158-162. 


\section{International Journal of Innovative Research in Medical Sciences (IJIRMS) \\ ISSN (Online): 2455-8737, page No. 207 to214 \\ Volume 01, Issue 05, July 2016}

12. Foster RH, Markham A. Levobupivacaine: a review of its pharmacology and use as a local anaesthetic. Drugs. 2000; 59: 551579.

13. Papagiannapoulou $\mathrm{P}$, Argiriadou $\mathrm{H}$, Georgiou M, Papaziagos B, Sfyra E, Kanakoudis F. Preincisional local infiltration of levobupivacaine vs ropivacaine for pain control after laparoscopic cholecystectomy. Surg Endosc. 2003; 17: 1961-1964.

14. Uzunkoy A, Coskun A, Akıncı OF. The value of preemptive analgesia in the treatment of postoperative pain after laparoscopic cholecystectomy. Eur Surg Res. 2001; 33: 39-41.

15. Hasaniya NW, Zayed FF, Faiz H, Severino R. Preinsertion local anesthesia at the trocar site improves perioperative pain and decreases costs of laparoscopic cholecystectomy. Surg Endosc. 2001; 15: 962-964.

16. Alessandri F, Lijoi D, Mistarngelo E, Niccoletti A, Ragni N. Effect of presurgical local infiltration of levobupivacain in the surgical field on postsurgical wound pain in laparoscopic gynecological surgery. Acta Obstet.Gynecol Scand.2006; 85: 844-849.

17. Hilvering B, Draaisma WA, van der Bilt JD, Valk RM, Kofman KE, Consten EC. Randomized clinical trial of combined preincisional infiltration and intraperitoneal instillation of levobupivacaine for postoperative pain after laparoscopic cholecystectomy. $\mathrm{Br} \mathrm{J}$ Surg. 2011; 98: 784-789.

18. Lee IO, Kim SH, Kong MH, Lee MK, Kim NS, Choi YS, Lim SH. Pain after laparoscopic cholecystectomy: the effect and timing of incisional and intraperitoneal bupivacaine. Can J Anaesth.2001; 48: 545-550.
19. Lee IO, Kim SH, Kong MH, Lee MK, Kim NS, Choi YS, Lim SH. Pain after laparoscopic cholecystectomy: the effect and timing of incisional and intraperitoneal bupivacaine. Can J Anaesth.2001; 48: 545-550.

20. Louizos AA, Hadzilia SJ, Leandros E, Kouroukli IK, Georgiou LG, Bramis JP. Postoperative pain relief after laparoscopic cholecystectomy: a placebo-controlled double-blind randomized trial of preincisional infiltration and intraperitoneal instillation of levobupivacaine $0.24 \%$.Surg Endosc. 2005; 19:1503-1506. 